
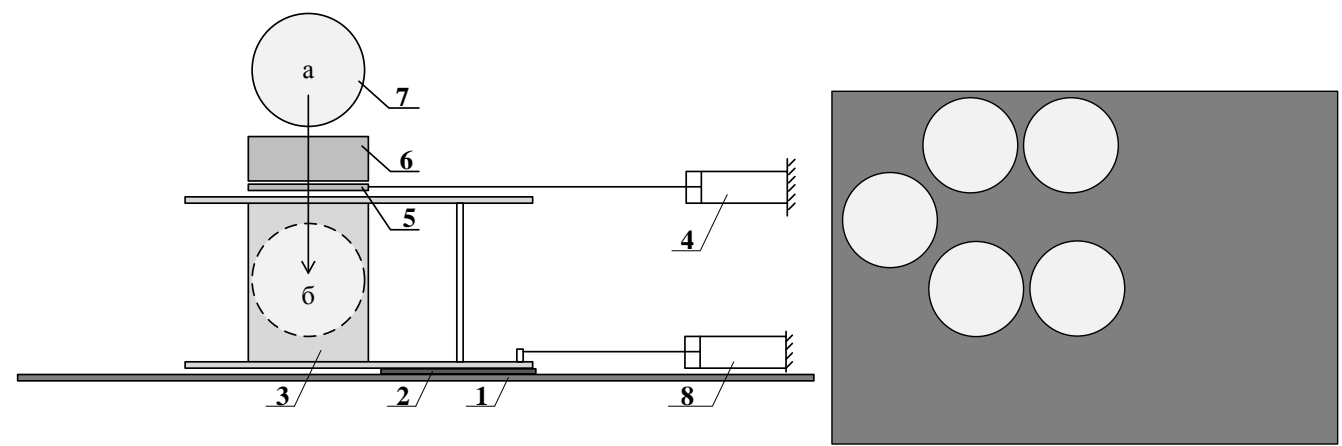

Fig. 7 - Type of Model in front

Fig. 8 - Type of a Platform from above

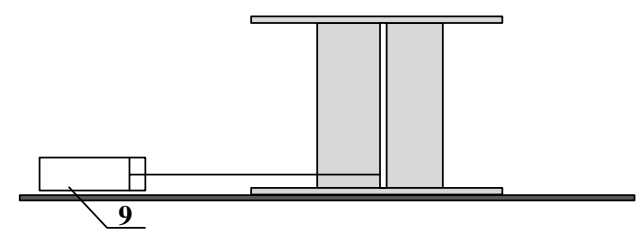

Fig. 9 - Type of Model at the left

\title{
Reference
}

[1] Owen. “Балаковский институт техники, технологии и управления - филиал ГОУ ВПО Саратовского Государственного технического университета," owen.ru. [Online]. Available: http://www.owen.ru/56504463. [Accessed: Oct. 31, 2016];

[2] Pstu.“Лабораторный стенд "Робот сортировщик", http://at.pstu.ru/view/Лабораторный_стенд:Робот-сортировщик. [Accessed: Oct. 31, 2016];

V. B. Yegorov, D. V. Putnikov, A. Yu. Latyshev, “Отчет о результатах конкурса, проведенного на базе НИЛ Мехатроники и робототехники и компании "Camozzi»," in Information technologies and automation: Proceedings for the 8-th annual scientific conference, 2015, Odessa, Ukraine, Oct. 15-16 2015, D. V. Putnikov, Eds.: Odessa: ONAFT, 2015. pp. 45-46.

\section{IMPROVED MODELS AND METHOD OF POWER CHANGE OF NPP UNIT WITH VVER-1000}

\section{T. Foshch ${ }^{1}$, S. Pelykh²}

${ }^{1,2}$ Odessa National Polytechnic University

ORCID: ${ }^{1}$ 0000-0001-8801-0382; ${ }^{2} 0000-0003-1608-8089$

E-mail: 1antariuz@gmail.com; ${ }^{2}$ pelykh@i.ua

Copyright (C) 2014 by author and the journal "Automation technological and business - processes". This work is licensed under the Creative Commons Attribution International License (CC BY). http://creativecommons.org/licenses/by/4.0/

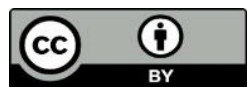

ONAFT

Open Access

Abstract: This study represents the improved mathematical and imitational allocated in space multi-zone model of VVER- 
1000 which differs from the known one. It allows to take into account the energy release of ${ }^{235} U$ nuclei fission as well as ${ }^{239} \mathrm{Pu}$. Moreover, this model includes sub-models of simultaneous control impact of the boric acid concentration in the coolant of the first circuit and the position of $9^{\text {th }}$ group control rods which allows to consider it as the model with allocated parameters and also allows to monitor changes in the mentioned technological parameters by reactor core symmetry sectors, by layers of reactor core height and by fuel assembly group each symmetry sector. Moreover, this model allows to calculate important process-dependent parameters of the reactor (including axial offset) as quantitative measure of its safety. As the mathematical and imitational models were improved, it allows to take into account intrinsic properties of the reactor core (including transient processes of xenon) and thus reduce the error of modelling static and dynamic properties of the reactor.

The automated control method of power change of the NPP unit with VVER-1000 was proposed for the first time. It uses three control loops. One of which maintains the regulatory change of reactor power by regulating the concentration of boric acid in the coolant, the second circuit keeps the required value of axial offset by changing the position of control rods, and the third one holds constant the coolant temperature mode by regulating the position of the main turbo generator valves.

On the basis of the above obtained method, two control programs were improved. The first one is the improved control program that implements the constant temperature of the coolant in the first circuit and the second one is the improved control program that implements the constant steam pressure in the second circuit.

Keywords: method of automated control, control models and methods, mathematical model, ${ }^{235} \mathrm{U},{ }^{239} \mathrm{Pu}$, three control loops, automatic control system, VVER-1000.

\section{Introduction}

The urgency of the work is that Ukrainian NPPs are used in the power system in order to cover the base load in the daily load schedule of the power system. However, nowadays, peak and semi-peak loads of the power system are provided by hydroelectric pumped storage power plants by $5 \%$, and a sufficient condition is $20 \%$. Therefore, it is required to use the maneuvering properties of nuclear power plants (NPP), which will allow to reconcile the change in consumption and generation of electrical energy. At present time, the task of adapting the existing power units to maneuvering work conditions is urgent. It may be reached by creating control methods and power regulation systems for power units of NPP which together will allow to operate the NPP in the load-following mode.

Since the task of maneuvering power in automatic mode is complex, it is necessary to improve the automated control system (ACS) by taking into account the inherent physical factors of NPP [1]. This is primarily a consideration of the operating time of ${ }^{239} \mathrm{Pu}$ and the formation of its fission products. The existing ACS of the NPP is based on ${ }^{235} \mathrm{U}$ characteristics only, assuming that ${ }^{239} \mathrm{Pu}$ characteristics are close to them. Power maneuvering at a nuclear power plant takes place with the help of operators in manual mode. However, constantly changing the power in manual mode provides a greater probability of error due to the human factor.

\section{Problem definition and goal}

The most important task of power unit during its operation is to ensure the stability of the reactor in any mode. On the one hand, existing power control systems of the power unit ensure the regulation of nuclear power and can lead to harmonic fluctuations in parameters due to the fact that several control circuits are contradirectional in relation to each other. On the other hand, the reactor core (RC) a priori possesses internally inherent neutron-physical processes that ensure their harmonious variation of the so-called xenon oscillations, which manifest themselves when controlling the power by the absorbing rods of control and protection system [2]. When controlling the power of a liquid absorber such oscillations do not occur. The same oscillations occur when the inlet/outlet temperature of the coolant changes to/from the RC [3]. When the harmonic orientation coincides with regulation with xenon oscillations, a positive feedback of control occurs. The advent of such state during regulation determines the technical contradiction of this work.

The proposed work brings to your attention the solution of the revealed contradiction by creating a method and models for automatic control of the change in the power of the power unit of the NPP with VVER-1000. Therefore, the purpose of the study is to improve the power control system of the power unit of the NPP with VVER-1000, which will allow to change the reactor power automatically and make it impossible to change the process parameters spontaneously.

Achieving consistency made solution of research tasks:

- to investigate the properties of VVER-1000 reactor as the control object within the static power control program and the impact of internal and external disturbances at its stability;

- to develop multi-zone distributed in space model VVER-1000 reactor as the control object which includes the formation and release of energy from ${ }^{235} \mathrm{U}$ and ${ }^{239} \mathrm{Pu}$;

- develop a mathematical model of VVER-1000 as the control object, which will explore the dynamic characteristics of the process parameters of the reactor;

- develop a method of power control unit that will prevent fluctuations of process parameters and an automated system to improve control capacity of the power unit and conduct a study of parameters for internal and external perturbations.

3. Properties of NPP with VVER-1000 as a control object

The existing power control programs, advantages and disadvantages of each program, technological characteristics of the power units with VVER-1000 were analyzed. It is noted that existing control programs with such parameters as constant temperature of the coolant in the inlet of $\mathrm{RC}$ or constant vapor pressure in the second circuit make disturbances that can lead to 
loss of reactor sustainability by changing the power flux $[4,5,6]$. In addition, none of the control program when operating the reactor does not include properties due to internal endemic disturbances.

The existing algorithms and methods of ACS functioning power control unit were analyzed. A significant contribution to the theory and practice methods of power control unit made: V.A. Ivanov, M.P. Shalman, V.P. Severin, V.I. Plyutynskyy, M.O. Duel, V.J. Rotach, A.T. Podshybyakin and many others. Moreover, an analysis of slow xenon transients, characterized by positive feedback which showed that exercise redistribution of energy in the core was made. Such processes are described in reactor theory by A.D. Galanin, V. Orlov, L.N. Usachev, S.M. Feinberg, S.B. Shyhov, R.A. Bach, B. Davison, S. Chandrasekhar, Hopf, Karl Case, John. Lehner, R. Wing.

Also it was studied the impact of changes in power in a load following mode to axial offset (AO) which showed that it is necessary to create models and methods of power change of NPP with VVER-1000, which are able to calculate an energy release change during fission of ${ }^{235} \mathrm{U}$ and ${ }^{239} \mathrm{Pu}$ as well, for efficient and safe power control of power unit in a load following mode. The model should take into account typical for VVER-1000 internal disturbances characteristic of xenon oscillation. To create models and method of power change of NPP, it is necessary to form the control task of unit and develop an allocated in space VVER-1000 model of reactor as a control object.

4. Mathematical modeling of NPP with VVER-1000

The model of NPP unit unit $\left(R ; S G ; T G ; P L ; h_{R O D} ; C_{B O R} ; N_{E}\right)=\left(A O ; T_{R}^{\text {out }} ; T_{R}^{\text {in }} ; T_{R}^{a v} ; P_{s t}\right)$ includes the following elements: the steam generator model $S G\left(T_{S G}^{\text {in }}(\tau) ; G_{s t}(\tau)\right)=\left(T_{S G}^{\text {out }}(\tau) ; P_{s t}(\tau)\right)$; the model that takes into account the transport delay of the coolant that circulates in the pipes from the reactor to the steam generator and back in the opposite direction $P L\left(T_{S G}^{\text {out }}(\tau) ; T_{R}^{\text {out }}(\tau)\right)=\left(T_{R}^{\text {in }}(\tau) ; T_{S G}^{\text {in }}(\tau)\right)$; the turbine generator model $T G\left(P_{s t}(\tau) ; N_{E}\right)=\left(G_{s t}(\tau) ; N_{T}(\tau)\right)$; the reactor model $R\left(C_{B O R} ; T_{R}^{i n} ; h_{R O D} ; i ; x ; z\right)=\left(A O ; Q_{i, x_{s} z} ; T_{i, x_{z} z}^{\text {out }}\right)$, which allows to calculate changes of above mentioned technological parameters of control facility by the sectors in symmetry of $\mathrm{RC}$, by high layers of $\mathrm{RC}$ and the fuel assembly (FA) groups of each symmetry sector. Where $h_{R O D}$ - depth dive of the control rods, $\% ; C_{B O R}$ - current concentration of boric acid in the coolant $\mathrm{g} / \mathrm{kg} ; N_{E}$ - electric power of NPP, MW; $A O$ - axial offset, $\% ; T_{R}^{\text {out }}$ - coolant temperature at the output of the reactor, ${ }^{\circ} \mathrm{C}$; $T_{R}^{i n}$ - coolant temperature at the input of the reactor, ${ }^{\circ} \mathrm{C} ; T_{R}^{a v}$ - average temperature of the coolant, ${ }^{\circ} \mathrm{C} ; P_{s t}-$ steam pressure at the input of the steam turbine, $\mathrm{MPa} ; \mathrm{T}_{S G}^{i n}$ - coolant temperature at the input of the steam generator, ${ }^{\circ} \mathrm{C} ; G_{s t}-\mathrm{steam}$ flow, $\mathrm{kg} / \mathrm{sec}$; $T_{S G}^{\text {out }}$ - coolant temperature at the output of the steam generator, ${ }^{\circ} \mathrm{C} ; N_{T}$ - thermal power of the turbine, $\mathrm{MW} ; i, x, z-\mathrm{values}$ of technological parameters, accordingly in a RC unit cell, of the sectors of symmetry, of the RC high layers, of the FA groups of each symmetry sector; $Q_{i, x_{i} z}$ - the specific energy release of the fuel in a RC unit cell, $\% ; T_{i, x_{z} z}^{\text {out }}$ - coolant temperature at the output of a RC unit cell, ${ }^{\circ} \mathrm{C}$.

To further develop of the allocated in space structural reactor model were used the multi-zone reactor model with dispersed parameters [7]. For creating the allocated in space structural model of the reactor were taken following assumptions:

- Each core area height must be equal to 6 segments, which together compose the core;

- It is assumed that each segment will have four areas in each FA and it will be based on years of operation.

The mathematical model of reactor kinetics, which takes into account the change in the isotopic composition of fission reaction not only from ${ }^{235} \mathrm{U}$, but also from ${ }^{239} \mathrm{Pu}$, which formed in the $\mathrm{RC}$, supplemented by differential equations $1-4$ :

$$
\begin{aligned}
& \frac{d \Phi_{i, z, z}}{d \tau}=\frac{\left(\rho(\tau)-\beta_{e f}^{235_{U}}\right) \cdot \bar{\Phi}_{i, x, z}(\tau)}{l}+\sum_{j=1}^{6} \lambda_{j}^{235_{U}} \cdot C_{j}^{235_{U}}(\tau)
\end{aligned}
$$

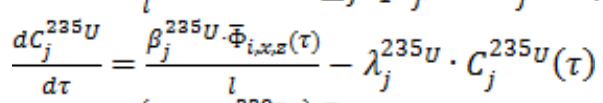

$$
\begin{aligned}
& \frac{d \Phi_{i, z, Z}}{d \tau}=\frac{\left(\rho(\tau)-\beta_{e f}^{239_{P u}}\right) \cdot \bar{\Phi}_{i, x, z}(\tau)}{l}+\sum_{g=1}^{6} \lambda_{g}^{239_{P u}} \times C_{g}^{239_{P u}}(\tau) \\
& \frac{d c_{g}^{239_{P u}}}{d \tau}=\frac{\beta_{g}^{239_{P u}} \bar{\Phi}_{i, x, z}(\tau)}{l}-\lambda_{g}^{239_{P u}}=C_{g}^{239_{P u}}(\tau)
\end{aligned}
$$

where $\rho(\tau)$ - reactivity of the reactor, in relative units; $\beta_{\text {ef }}$ - total part of delayed neutrons, in r.u.; $\beta_{\mathrm{j}}$ - part of neutrons which is emitting during the decay of $\mathrm{j}$-th nuclei, then $\beta=\Sigma_{j} \beta_{j} ; \lambda_{\mathrm{j}}$ - decay constant of $\mathrm{j}$-th predecessors of core predecessor of

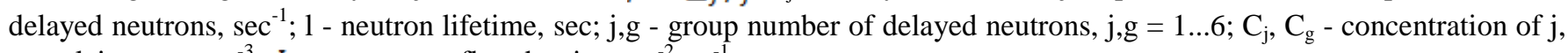
g nuclei group, $\mathrm{cm}^{-3} ; \Phi_{\mathrm{i}, \mathrm{x}, \mathrm{z}}-$ neutron flux density, $\mathrm{cm}^{-2} \mathrm{sec}^{-1}$.

Formation of ${ }^{239} \mathrm{Pu}$ from ${ }^{238} \mathrm{U}$ described by the following system of differential equations:

$$
\begin{aligned}
& \frac{d N_{i, x, z}^{238_{U}}}{d t}=-N_{i, x, z}^{238_{U}} \times \sigma_{f, 238_{U}} \cdot \bar{\Phi}_{i, x_{i} z}-N_{i, x, z}^{238_{U}} \cdot \sigma_{c, 238_{U}} \cdot \bar{\Phi}_{i, x, z} \\
& \frac{d N_{i, x, z}^{239_{U}}}{d t}=-N_{i, x, z}^{238_{U}} \cdot \sigma_{c_{s} 238_{U}} \cdot \bar{\Phi}_{i, x_{i} z}-\lambda_{238_{U}} \cdot N_{i, x_{i} z}^{239_{U}} \\
& \frac{d N_{i, x, z}^{239_{N p}}}{d t}=\lambda_{239_{U}} \cdot N_{i, x, z}^{239_{U}}-\lambda_{239_{N p}} \cdot N_{i, x, z}^{239_{N p}} \\
& \frac{d N_{i, x, z}^{239}}{d t}=\lambda_{239_{N p}} \cdot N_{i, x_{i} z}^{239_{N p}}-N_{i, x_{i} z}^{239_{P u}}=\sigma_{c_{s} 239_{P u}}=\bar{\Phi}_{i, x_{i} z}-N_{i, x_{i} z}^{239_{P u}}=\sigma_{f, 239_{P u}}
\end{aligned}
$$


where $N_{i, x_{z} Z}^{238_{U}}, N_{i, x_{i} Z}^{239_{N p}}, N_{i, x_{i} Z}^{239_{U}}$ - nuclear concentration of, accordingly, ${ }^{238} \mathrm{U},{ }^{239} \mathrm{~Np},{ }^{239} \mathrm{U}, \mathrm{cm}^{-3} ; \sigma_{f, 238_{U}}, \sigma_{f, 239_{P u}}-$ microscopic cross sections of the division of, accordingly, ${ }^{238} \mathrm{U},{ }^{239} \mathrm{Pu}, 10^{-24} \mathrm{~cm}^{2} ; \sigma_{c_{s} 238_{U}}, \sigma_{c_{s} 239_{P u}}$ - microscopic section of radiative capture, accordingly, ${ }^{238} \mathrm{U},{ }^{239} \mathrm{Pu}, 10^{-24} \mathrm{~cm}^{2}$.

Differential equations of ${ }^{135} \mathrm{Xe}$ generation velocity by fission of ${ }^{235} \mathrm{U}$ and ${ }^{239} \mathrm{Pu}$ were used, which are presented by 9-12:

$$
\begin{aligned}
& \frac{d N_{i, x, z}^{135_{I}}}{d t}=k \cdot \bar{\Phi}_{i, x_{i} z} \cdot \sigma_{f, 235_{U}} \cdot N_{i_{s}, x_{i} z}^{235_{U}}-\lambda_{135_{I}} \cdot N_{i, x_{i} z}^{135_{I}} \\
& \frac{d N_{i, x, z}^{135_{X e}}}{d t}=\lambda_{135_{I}} \cdot N_{i, x_{i} z}^{135_{I}}-\lambda_{135_{X e}} \cdot N_{i, x_{i} z}^{135_{X e}}-\bar{\Phi}_{i, x_{i}, z^{2}} \cdot \sigma_{a, 135_{X e}} \cdot N_{i, x_{i} z}^{135_{X e}} \\
& \frac{d N_{i, z, z}^{135_{I}}}{d t}=k \cdot \bar{\Phi}_{i, x_{i}, z} \cdot \sigma_{f, 239_{P u}} \cdot N_{i, x, z}^{239_{P u}}-\lambda_{135_{I}} \cdot N_{i, x_{i} z}^{135_{I}}
\end{aligned}
$$

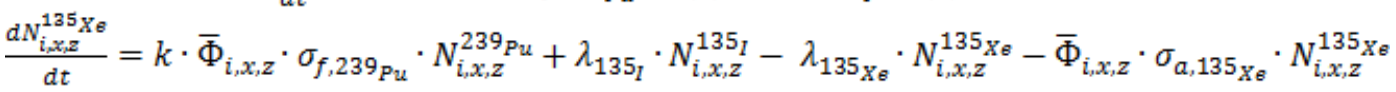

where $\mathrm{k}$ - formation probability of of neutrons during fission.

Table 1 shows the probability of ${ }^{235} \mathrm{U}$ and ${ }^{239} \mathrm{Pu}$ fission into fragments element of ${ }^{135} \mathrm{I}$ and ${ }^{135} \mathrm{Xe}$.

\section{Table 1 - Probabilities of ${ }^{235} \mathrm{U}$ and ${ }^{239} \mathrm{Pu}$ fission into fragments element of ${ }^{135} \mathrm{Xe}$ and ${ }^{135} \mathrm{I}$}

\begin{tabular}{|l|l|l|}
\hline & ${ }^{235} U$ & ${ }^{239} \mathrm{Pu}$ \\
\hline${ }^{135} \mathrm{I}$ & $6.29 \%$ & $6.5354 \%$ \\
\hline${ }^{135} \mathrm{Xe}$ & $0.2576 \%$ & $1.0763 \%$ \\
\hline
\end{tabular}

The mathematical model of energy release in a RC unit cell, which consists of obtained energy during nuclear fission ${ }^{235} \mathrm{U}$ and ${ }^{239} \mathrm{Pu}$ as well, was developed:

$$
\begin{gathered}
Q_{i, x_{i} z}(\tau)=\sum\left(Q_{i, x_{i} z}^{235_{U}}(\tau)+Q_{i, x_{i} z}^{239_{P u}}(\tau)\right) \\
Q_{i, x_{i} z}^{235_{U}}(\tau)=\left(\left(\varepsilon_{l}^{i n}+\varepsilon_{d}^{i n}\right)_{U}+\left(\varepsilon_{l}^{g}+\varepsilon_{d}^{g}\right)_{U} \cdot q_{s t}(\tau)\right) \cdot \bar{\Phi}_{i, x_{i} z}(\tau) \cdot v \cdot V_{i, x_{i} z}^{f} \cdot \Sigma_{f}^{5} \cdot E_{f}^{5} \\
Q_{i, x_{i} z}^{239_{P u}}(\tau)=\left(\left(\varepsilon_{l}^{i n}+\varepsilon_{d}^{i n}\right)_{U}+\left(\varepsilon_{l}^{g}+\varepsilon_{d}^{g}\right)_{P u} \times q_{s t}(\tau)\right) \cdot \bar{\Phi}_{i, x_{i} z}(\tau) \cdot v \cdot V_{i_{u} x_{i} z}^{f} \cdot \Sigma_{f}^{9} \cdot E_{f}^{9}
\end{gathered}
$$

where $\varepsilon_{l}^{i n}$ - part of instantaneous local heat release, in r.u.; $\varepsilon_{d}^{i n}$ - part of multiple instant heat release, in r.u.; $\varepsilon_{l}^{g}-$ part of gradual local heat release, in r.u.; $\varepsilon_{d}^{g}$ - part of gradually diffused heat release, in r.u.; $v$ - neutrons velocity concerning cores $\mathrm{cm} / \mathrm{sec} ; V_{f}$ - volume of fuel, $\mathrm{cm}^{3} ; \Sigma_{f}^{5}, \Sigma_{f}^{9}$ - macroscopic fission section, accordingly, ${ }^{235} \mathrm{U},{ }^{239} \mathrm{Pu}, \mathrm{cm}^{-1} ; E_{f}^{5}, E_{f}^{9}-$ energy fission of one core, accordingly, ${ }^{235} \mathrm{U},{ }^{239} \mathrm{Pu}, \mathrm{J} ; q_{s t}(\tau)$ - relative power of gradual heat release, in parts of $\mathrm{Q}(\tau)$.

For obtaining the heating coolant mathematical model, the following differential equations were used:

$$
\begin{aligned}
& Q_{i, x_{z} z}(\tau)=C p_{f} \times m_{i, x, z}^{f} \frac{d t_{i, x, z}^{f}}{d \tau}+\alpha \cdot F_{i, x, z} \cdot\left(t_{i, x, z}^{f}(\tau)-t_{i, x, z}^{a v}(\tau)\right) \\
& \left.\alpha \cdot F_{i_{z}, x_{i} z} \cdot\left(t_{i, x, z}^{f}(\tau)-t_{i, x_{i} z}^{a v}(\tau)\right)=C p_{w} \cdot m_{i, x_{i} z}^{w} \frac{d t_{i, x, z}^{a v}}{d \tau}+\frac{2 \cdot C p_{w} \cdot m_{i, x, z}^{w}}{\tau_{0}} \cdot\left(t_{i, x, z}^{a v}(\tau)-t_{i_{x}, x_{i} z}^{i n}(\tau)\right)\right)
\end{aligned}
$$

where $C p_{f}-$ specific heat consumption, $J /(\mathrm{kg} \cdot \mathrm{K}) ; m_{i, x z}^{f}-$ mass of fuel in a RC unit cell, $\mathrm{kg}$; $\alpha-$ convective heat exchange coefficient, $W /\left(m^{2} \times K\right) ; \mathrm{F}_{\mathrm{i}, \mathrm{x}, \mathrm{z}}$ - heat exchange volume in a RC unit cell, $\mathrm{m}^{2} ; t_{i, x, z}^{f}(\tau)$ - fuel temperature in a RC unit cell, ${ }^{\circ} \mathrm{C} ; t_{i, x, z}^{a v}(\tau)$ - average temperature in a RC unit cell, ${ }^{\circ} \mathrm{C} ; C p_{w}-$ specific thermal capacity of coolant, $I /(\mathrm{kg} \cdot K) ; m_{i, x, z}^{w}-$ mass of coolant in a RC unit cell, $\mathrm{kg} ; t_{i, x_{i} z}^{i n}(\tau)$ - coolant temperature at the input of a $\mathrm{RC}$ unit cell, ${ }^{\circ} \mathrm{C}$; $\tau_{0}-$ transit time of coolant through a RC unit cell, sec.

Reactor reactivity is the sum of effects:

$$
\rho_{i, x_{i} z}^{S U M}(\tau)=\rho_{i, x_{i} z}^{R O D}+\rho_{i, x_{i} z}^{B O R}+\rho_{i, x_{i} z}^{N}+\rho_{i, x_{i} z}^{X e}+\rho_{i, x_{i} z}^{T}
$$

where $\rho_{i, x_{i} z}^{R O D}, \rho_{i, x_{z} z}^{B O R}, \rho_{i, x_{i} z}^{N}, \rho_{i, x_{i}, z}^{X e}, \rho_{i, x_{i} z}^{T}$ - effect of reactivity introduced, accordingly, by group of the control rods, by concentration of boric acid in the coolant of the first circuit, by reactor power change, by poisoners concentration in the fuel, by coolant temperature change of the 1 st circuit.

To calculate the reactivity introduced by group of the control rods, the following equation was used:

$$
\rho_{i, x_{i} z}^{R O D}(\tau)=\alpha_{i, x_{i}, z^{*}}^{k}\left(h-h_{i, x_{i} z}^{0}\right)
$$

where $\alpha_{i, x, z}^{k}$ - coefficient of characteristic inclination in a RC unit cell, $1 / \mathrm{cm} ; h$ - depth dive of the control rods in the RC, $\mathrm{cm} ; h_{i, x_{i} z}^{0}-$ start zone and part from bottom of a RC unit cell, $\mathrm{cm}$.

To calculate the effect of reactivity, which introduced by the concentration of boric acid in the coolant of the first circuit, the differential equation was used: 


$$
\rho_{i, x, z}^{B O R}\left(C_{i, x, z}^{B O R}\right)=\int_{0}^{C} \alpha_{i, x, z}^{B O R} \partial C_{i, x, z}^{B O R}
$$

where $\alpha_{i, x, z}^{B O R}=f(C)=\frac{\partial \rho_{i, x, z}^{B O R}}{\partial c_{i, x, z}^{B O R}}-$ reactivity coefficient of boric acid.

Changing the concentration of boric acid in the coolant in case of:

- injecting boric acid solution

- injecting demineralized water

$$
T_{4} \cdot \frac{\partial c_{i, x, z}^{B O R}}{\partial \tau}+\Delta C_{i, x, z}^{B O R}=k_{4} \cdot \Delta G_{i, x, z}^{B O R}
$$

$$
T_{5} \cdot \frac{\partial c_{i, x, z}^{B O R}}{\partial \tau}+\Delta C_{i, x_{i} z}^{B O R}=k_{5} \cdot \Delta G_{i, x ; z}^{H 2 O}
$$

where $C_{i, x, z}^{B O R}$ - concentration of boric acid; $k_{4}, k_{5}$ - transfer coefficients; $T_{4}, T_{5}$ - time constants; $\Delta G_{i, x, z}^{B O R}-$ flow rate change of boric acid; $\Delta G_{i, x, z}^{H 2 O}$ - flow rate change of demineralized water.

The effect of reactivity introduced by reactor power change is described by the following differential equation:

$$
\rho_{i, x_{i} z}^{N}(N)=\int_{0}^{N} \alpha_{i, x_{i} z}^{N} \partial N
$$

Calculation of reactivity changes due to xenon poisoning from producing and fission reactions of ${ }^{239} \mathrm{Pu}$, and from ${ }^{235} \mathrm{U}$ as well, defined by the expression of differential equations:

$$
\begin{aligned}
& \rho_{i, x, z}^{X e_{i}, U}(\tau)=-\frac{\sigma_{a}^{X e} \cdot \theta}{\sigma_{a}^{5} \cdot N_{5}} \cdot N_{i, x_{i} z}^{X e}(\tau) \\
& \rho_{i, x, z}^{X e_{i}, P u}(\tau)=-\frac{\sigma_{a}^{X e} \cdot \theta}{\sigma_{a}^{9} \cdot N_{9}} \cdot N_{i, x, z}^{X e}(\tau)
\end{aligned}
$$

where $\sigma_{a}^{X e}, \sigma_{a}^{5}, \sigma_{a}^{9}-$ microscopic cross section absorption of thermal neutron by atoms, accordingly, ${ }^{135} \mathrm{Xe},{ }^{235} \mathrm{U},{ }^{239} \mathrm{Pu}$, $\mathrm{cm}^{2} ; \mathrm{N}_{5}, \mathrm{~N}_{9}$ - concentration of atoms, accordingly, ${ }^{235} \mathrm{U},{ }^{239} \mathrm{Pu}, \mathrm{cm}^{-3} ; N_{i, x_{z} z}^{X e}(\tau)$ - equilibrium concentration of atoms ${ }^{135} X e, \mathrm{~cm}^{3}$; $\theta$ - coefficient of using thermal neutrons in not poisoned reactor.

To calculate the effect of reactivity introduced by coolant temperature of the first circuit, the following differential equation was used:

$$
\rho_{i, x_{i} z}^{T}(T)=\int_{20^{\circ}}^{T} \alpha_{i_{s}, x_{z} z}^{T} \partial T
$$

In addition, to the following equations 1-26 was applied a division by height layer of RC (i), by sectors of $60^{\circ}$ symmetry segment (x) and by group areas of FA within the sector $(\mathrm{z})$.

5. Simulation of NPP with VVER-1000

To make imitation model, the simulation development environment Simulink, which is part of the software Matlab [License 14 AE K761327 VD, 308,918], was used. Using differential equations 1-26 the corresponding simulation models were built which allow to simulate the necessary processes associated with RC of reactor. Figure 1 shows an illustration of the simulation model diagram of a FA group symmetry sector within the symmetry sector and vertical layer of RC that allows to simulate NPP model with VVER-1000 and allocated RC.

As seen in Figure 1, the model of a FA group symmetry sector within the symmetry sector and vertical layer of RC consists of 26 differential equations, 3 input parameters $\left(h_{i, x_{i} z}^{0}, C_{i, x, z}^{B O R}, \mathrm{~T}_{i, x_{i} z}^{i n}\right)$ and 4-output parameters $\left(\Phi_{i, x_{i} z}, \mathrm{Q}_{i, x_{i} z}, \mathrm{~T}_{i_{z}, x_{i} z}^{\text {out }}, \mathrm{T}_{i, x_{z},}^{f}\right)$. The behavior of neutron field depends on the formed reactivity effects that are shown in Figure 1. These inherent effects of reactivity are able to change thermal power without control system. Therefore, an important goal is to control the change of reactivity, as they affect to the stability of the reactor during the transition from one power level to another.

Thus, the simulation model with allocated RC was implemented in frame of the Simulink environment. This simulation model contains a large number of subsystems, because it has a complicated tree structure, called subsystems. Although each subsystem identical and obvious to another, but with different initial and input settings. Moreover, the implemented tree structure with allocated parameters allow to make a simulation of allocated RC of VVER-1000 in frame of a load following mode.

Figure 2 illustrates a diagram of a simulation NPP model with VVER-1000 and with allocated RC which is implemented in frame of the Simulink environment.

To calculate the output parameters of the model as $O, \Phi_{i, x_{i},}, \mathrm{Q}_{i, x_{i} z}, \mathrm{~T}_{i_{z}, x_{i} Z}^{\text {out }}, \mathrm{T}_{i_{u}, x_{i},}^{f}$ the following equations were used:

$$
\begin{aligned}
& A O=\frac{\left(\sum_{i=6}^{10} \sum_{z=1}^{6} \sum_{z=1}^{4}\left(Q_{i, z, z}^{T O P}\right)\right)-\left(\sum_{i=1}^{5} \sum_{x=1}^{6} \sum_{z=1}^{4}\left(Q_{i, x, z}^{B O T}\right)\right)}{\left(\sum_{i=6}^{10} \sum_{z=1}^{6} \sum_{z=1}^{4}\left(Q_{i, x, z}^{T O P}\right)\right)+\left(\sum_{i=1}^{5} \sum_{x=1}^{6} \sum_{z=1}^{4}\left(Q_{i, x, z}^{B O T}\right)\right)} \cdot 100 \% \\
& \Phi_{i, x_{i} z}=\left(\sum_{i=1}^{10} \sum_{x=1}^{6} \sum_{z=1}^{4}\left(\Phi_{i, x, z}\right)\right) \\
& \mathrm{Q}_{i, x_{i} z}=\left(\sum_{i=1}^{10} \sum_{x=1}^{6} \sum_{z=1}^{4}\left(\mathrm{Q}_{i, x_{i} z}\right)\right) \\
& \mathrm{T}_{i, x, z}^{\text {out }}=\frac{\left(\sum_{i=10}^{10} \sum_{x=1}^{6} \sum_{z=1}^{4}\left(T_{i, x, z}^{\text {out }}\right)\right)}{\left(\sum_{i=10}^{10} i\right)+\left(\sum_{x=1}^{6} x\right)+\left(\sum_{z=1}^{4} z\right)} \\
& \mathrm{T}_{i_{x} x_{i} z}^{f}=\frac{\left(\sum_{i=1}^{10} \sum_{x=1}^{6} \Sigma_{z=1}^{4}\left(\mathrm{~T}_{i, z, z}^{f}\right)\right)}{\left(\sum_{i=1}^{10} \overline{1}\right)+\left(\sum_{z=1}^{6} x\right)+\left(\sum_{z=1}^{4} z\right)}
\end{aligned}
$$




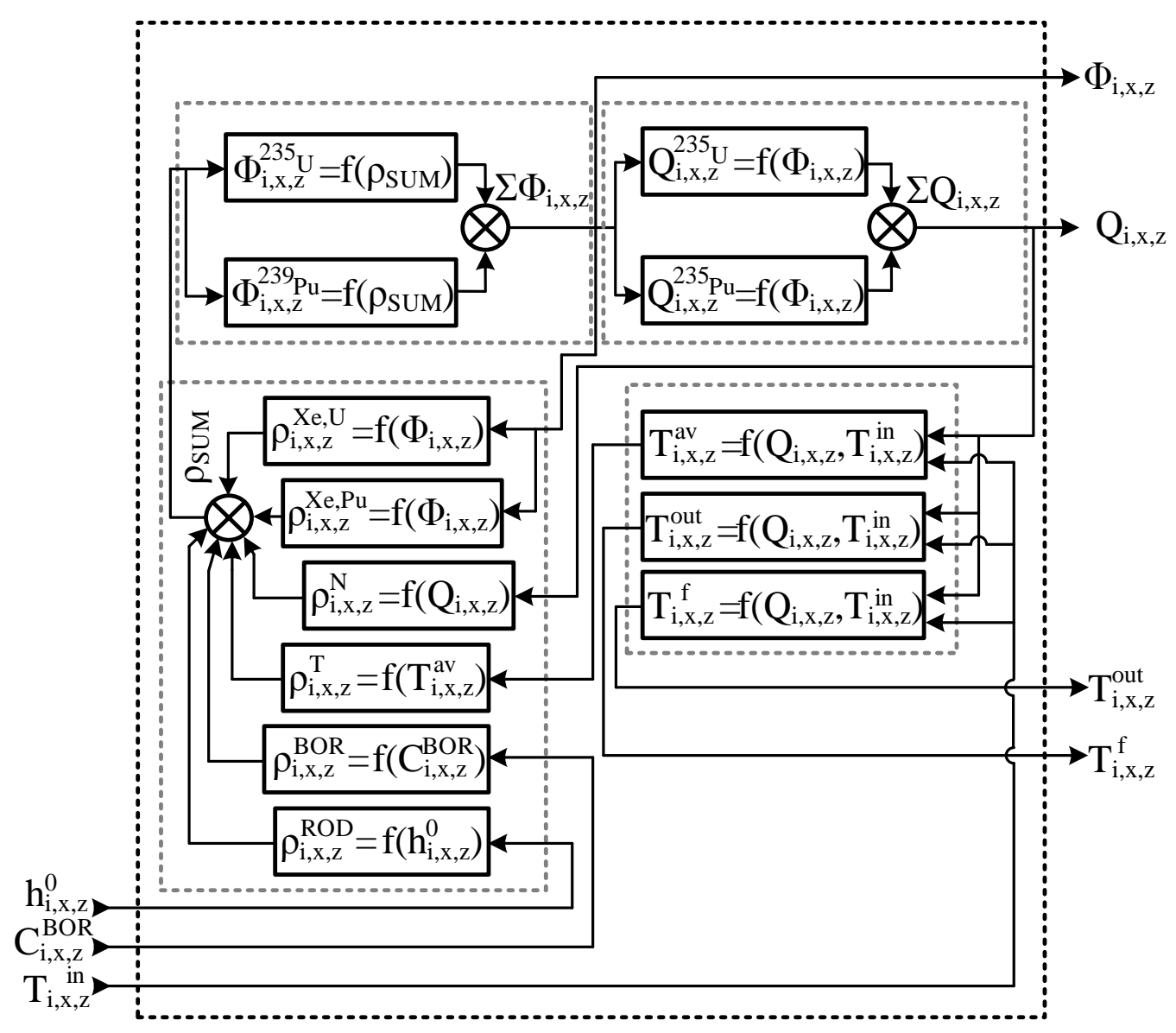

Fig. 1 - Diagram of the simulation model proposed RC unit cell

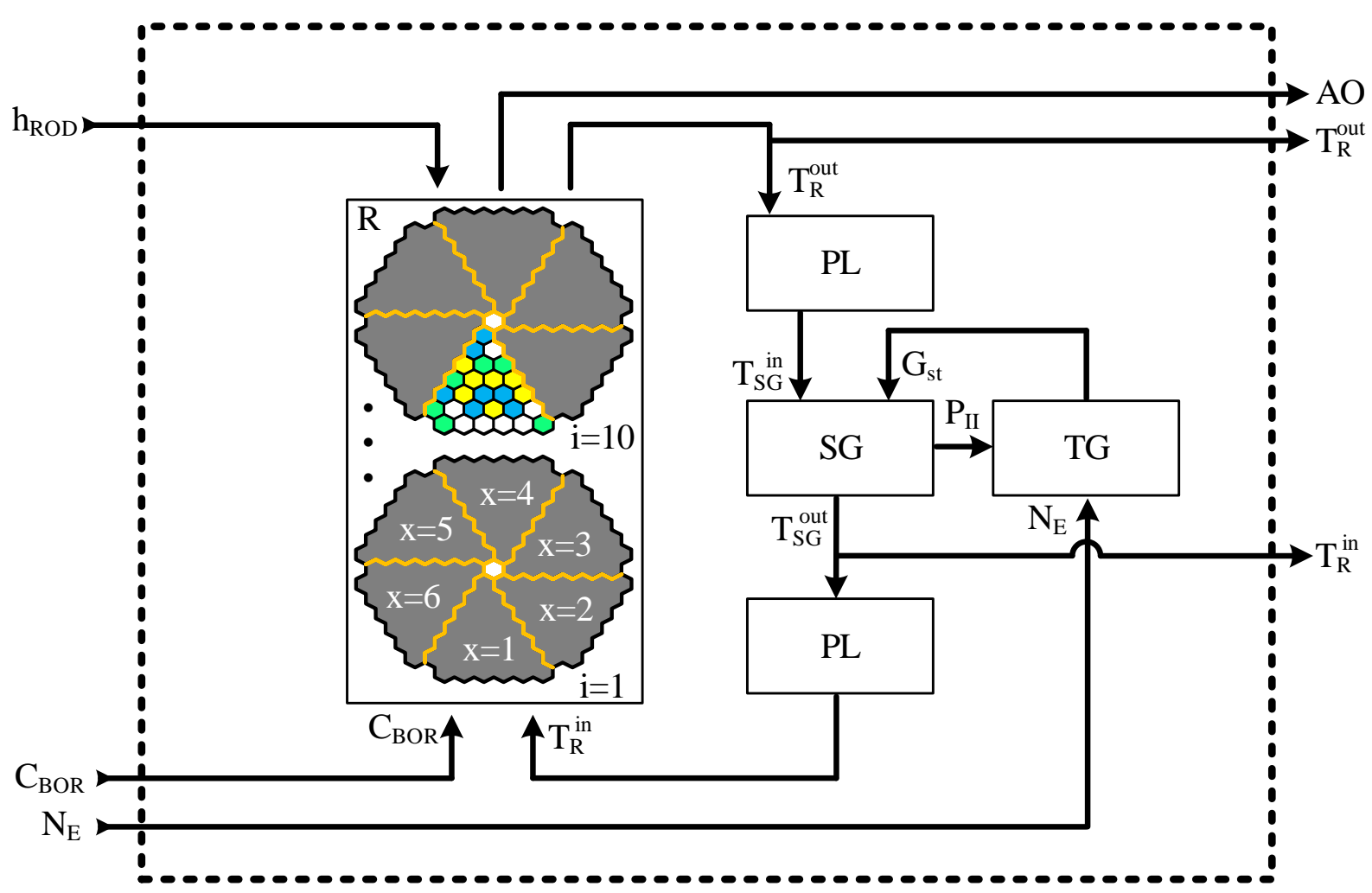

Fig. 2 - NPP simulation model VVER-1000 with allocated RC and without controllers 
6. The automated control method of VVER-1000 power change

To ensure a steady state of NPP with VVER-1000 it is necessary to maintain a constant value of AO while changing the field of energy release which can adversely affect the reactor facility as a whole due to internal disturbances and inherent properties of the RC. So at first it was proposed the method of automated control of power change at NPP with VVER-1000 which uses three control loops:

- supports routine change of reactor power by regulating the concentration of boric acid in the coolant;

- supports AO desired value by changing the position of control rods;

- supports the coolant temperature conditions by controlling the position of the main valve turbo.

Regulation method for automated control of power change at NPP with VVER-1000 are:

- the controller of axial offset should influence to the control rods, and power must be maintained by means of the concentration of boric acid;

- for extra pit iodine concentration of boric acid should remain unchanged at low power value, that the regulator should not respond to changing capacity;

- the return unit for maximum power concentration of boric acid should be different from the original value that was before the maneuver to compensate for changes in the concentration of $135 \mathrm{Xe}$ and 135I caused maneuver.

- the regulator should take into account nonlinear properties of the object of regulation;

- work with regulators involved are necessary.

In order to determine the dynamic characteristics of the main technical parameters of the power unit with intermittent disturbances used the results of 4 experiments conducted at Unit №3 Southern NPP, namely:

- change of turbine control valves;

- change of the position of the control rods.

These data are not of statistical nature, so check the adequacy of statistical methods (criteria) is not possible. Given the above, it was decided to assess the degree of difference data obtained through simulations with experimental data by calculating the relative error modeling at this interval. The disturbance was caused by the control rods during the experiment and moving of the control rods in the RC was carried out continuously, down about $10 \%$ of the its height.

For analytical curve shown in Figure 3. The average relative error is $\delta=0.000944$. The maximum relative error is $\delta_{\max }=$ 0.0015. Compared with multi zone mathematical model with lumped parameters, developed by Tsyselska T.A., the average relative error is $\delta=0.0024$, and the maximum relative error is $\delta_{\max }=0.0092$. The relative error point curve of reactor power with the introduction of the control rods are shown in Table 2. There were calculated relative simulation error changes coolant temperature at the output of the RC and changing electrical power unit, given in Tables 3 and 4.

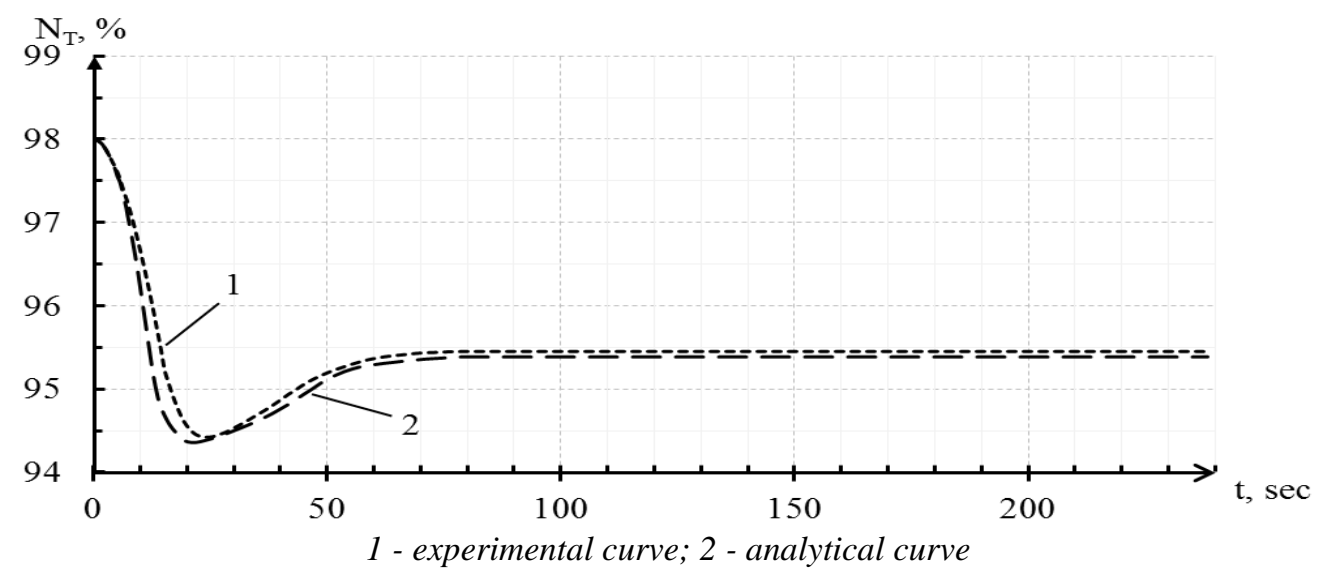

Fig. 3 - Effect of the control rods, which are introduced in the $\mathrm{RC}$, to change of the neutron reactor power

During daily maneuvers of unloading up to $80 \%$ of the rated power of advanced automated control programs of power change of NPP with ACS, which operates with the program of constant average water temperature of the 1st circuit and with the program of constant steam pressure in the 2 nd circuit, the comparison operations were made.

Table 2 - Relative errors of point's curve of reactor power when the control rods are injected

\begin{tabular}{|c|c|c|c|c|c|c|c|c|c|}
\hline $\mathbf{i}$ & $\boldsymbol{\delta}$ & $\mathbf{i}$ & $\boldsymbol{\delta}$ & $\mathbf{I}$ & $\boldsymbol{\delta}$ & $\mathbf{i}$ & $\boldsymbol{\delta}$ & $\mathbf{i}$ & $\boldsymbol{\delta}$ \\
\hline $\mathbf{1}$ & 0 & $\mathbf{6}$ & 0.001 & $\mathbf{1 1}$ & 0.001 & $\mathbf{1 6}$ & 0.001 & $\mathbf{2 1}$ & 0.001 \\
\hline $\mathbf{2}$ & 0.0011 & $\mathbf{7}$ & 0.001 & $\mathbf{1 2}$ & 0.001 & $\mathbf{1 7}$ & 0.001 & $\mathbf{2 2}$ & 0.001 \\
\hline $\mathbf{3}$ & 0.0015 & $\mathbf{8}$ & 0.001 & $\mathbf{1 3}$ & 0.001 & $\mathbf{1 8}$ & 0.001 & $\mathbf{2 3}$ & 0.001 \\
\hline $\mathbf{4}$ & 0 & $\mathbf{9}$ & 0.001 & $\mathbf{1 4}$ & 0.001 & $\mathbf{1 9}$ & 0.001 & $\mathbf{2 4}$ & 0.001 \\
\hline $\mathbf{5}$ & 0.001 & $\mathbf{1 0}$ & 0.001 & $\mathbf{1 5}$ & 0.001 & $\mathbf{2 0}$ & 0.001 & $\mathbf{2 5}$ & 0.001 \\
\hline
\end{tabular}


Table 3 - Relative errors of point's curve of the coolant temperature at the output of the reactor when the control rods are injected

\begin{tabular}{|c|c|c|c|c|c|c|c|c|c|}
\hline $\mathbf{i}$ & $\boldsymbol{\delta}$ & $\mathbf{i}$ & $\boldsymbol{\delta}$ & $\mathbf{I}$ & $\boldsymbol{\delta}$ & $\mathbf{i}$ & $\boldsymbol{\delta}$ & $\mathbf{i}$ & $\boldsymbol{\delta}$ \\
\hline $\mathbf{1}$ & 0 & $\mathbf{6}$ & 0.0011 & $\mathbf{1 1}$ & 0.001 & $\mathbf{1 6}$ & 0.001 & $\mathbf{2 1}$ & 0.001 \\
\hline $\mathbf{2}$ & 0.001 & $\mathbf{7}$ & 0.001 & $\mathbf{1 2}$ & 0.001 & $\mathbf{1 7}$ & 0.001 & $\mathbf{2 2}$ & 0.001 \\
\hline $\mathbf{3}$ & 0.0014 & $\mathbf{8}$ & 0.001 & $\mathbf{1 3}$ & 0.001 & $\mathbf{1 8}$ & 0.001 & $\mathbf{2 3}$ & 0.001 \\
\hline $\mathbf{4}$ & 0.0015 & $\mathbf{9}$ & 0.001 & $\mathbf{1 4}$ & 0.001 & $\mathbf{1 9}$ & 0.001 & $\mathbf{2 4}$ & 0.001 \\
\hline $\mathbf{5}$ & 0.0013 & $\mathbf{1 0}$ & 0.001 & $\mathbf{1 5}$ & 0.001 & $\mathbf{2 0}$ & 0.001 & $\mathbf{2 5}$ & 0.001 \\
\hline
\end{tabular}

Table 4 - Relative errors of point's curve of the power unit when the control rods are injected

\begin{tabular}{|c|c|c|c|c|c|c|c|c|c|}
\hline $\mathbf{i}$ & $\boldsymbol{\delta}$ & $\mathbf{i}$ & $\boldsymbol{\delta}$ & $\mathbf{I}$ & $\boldsymbol{\delta}$ & $\mathbf{i}$ & $\boldsymbol{\delta}$ & $\mathbf{i}$ & $\boldsymbol{\delta}$ \\
\hline $\mathbf{1}$ & 0 & $\mathbf{6}$ & 0.0011 & $\mathbf{1 1}$ & 0.0013 & $\mathbf{1 6}$ & 0.001 & $\mathbf{2 1}$ & 0.001 \\
\hline $\mathbf{2}$ & 0 & $\mathbf{7}$ & 0.0013 & $\mathbf{1 2}$ & 0.001 & $\mathbf{1 7}$ & 0.001 & $\mathbf{2 2}$ & 0.001 \\
\hline $\mathbf{3}$ & 0.0008 & $\mathbf{8}$ & 0.0015 & $\mathbf{1 3}$ & 0.001 & $\mathbf{1 8}$ & 0.001 & $\mathbf{2 3}$ & 0.001 \\
\hline $\mathbf{4}$ & 0 & $\mathbf{9}$ & 0.0016 & $\mathbf{1 4}$ & 0.001 & $\mathbf{1 9}$ & 0.001 & $\mathbf{2 4}$ & 0.001 \\
\hline $\mathbf{5}$ & 0.001 & $\mathbf{1 0}$ & 0.0016 & $\mathbf{1 5}$ & 0.001 & $\mathbf{2 0}$ & 0.001 & $\mathbf{2 5}$ & 0.001 \\
\hline
\end{tabular}

The comparing results of power unit changes, the positions of the control rods and AO during the daily maneuver with control program of constant average water temperature of the 1st circuit, are shown in Figure 5-7. The comparing results of the positions of the control rods and AO during the daily maneuver with control program of constant pressure of steam in the $2^{\text {nd }}$ circuit, are shown in Figure 8, 9. The result of power change of power unit during the daily maneuver with control program of constant pressure of steam in the $2^{\text {nd }}$ circuit does not require to be shown. It can be explained that the transition process of power change coincides with the transition process, which is shown in Figure 6.

To implement the advanced ACS of power change of power unit, the parameters of axial offset controllers, the controllers of average coolant temperature in the first circuit, the controllers of pressure in the second circuit and the controllers of power was obtained by Kopelovych method.

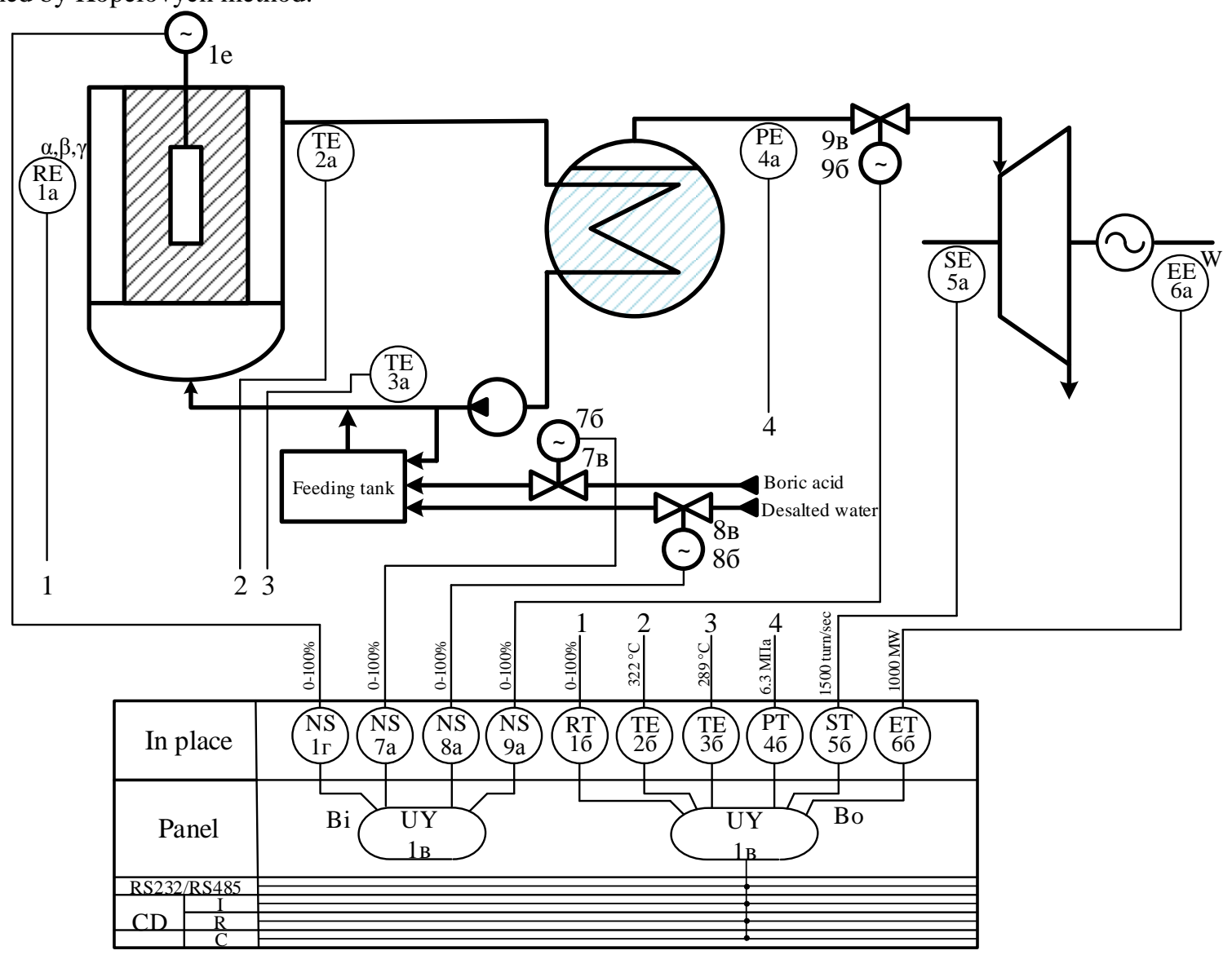

Fig. 4 - Advanced diagram of two automated control programs with constant average water temperature of the $1^{\text {st }}$ circuit and with constant steam pressure in the $2^{\text {nd }}$ circuit 


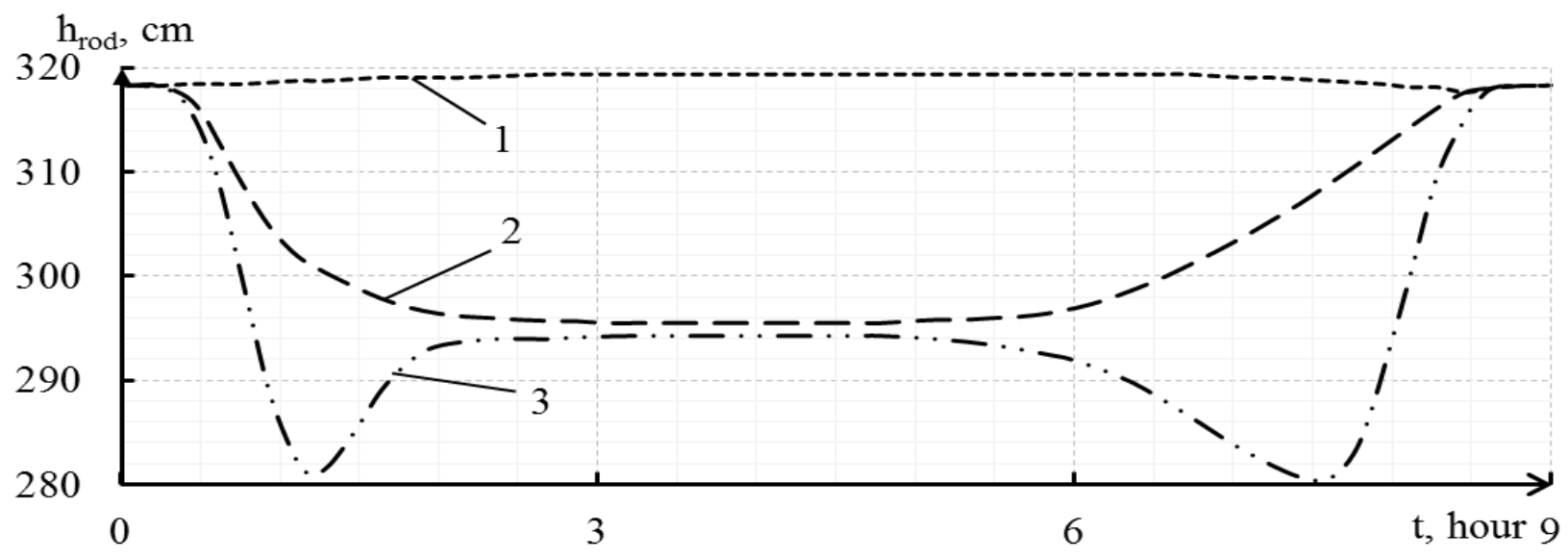

1 - improved ACS with constant average water temperature of the $1^{\text {st }}$ circuit; 2 - improved ACS with constant average water temperature of the $1^{\text {st }}$ circuit, which is designed by Tsyselska T.A.; 3 - primary ACS with constant average water temperature of the $1^{\text {st }}$ circuit

Fig. 5 - The result of changes in the power unit during the daily maneuver with improved ACS of constant average water temperature of the 1 st circuit

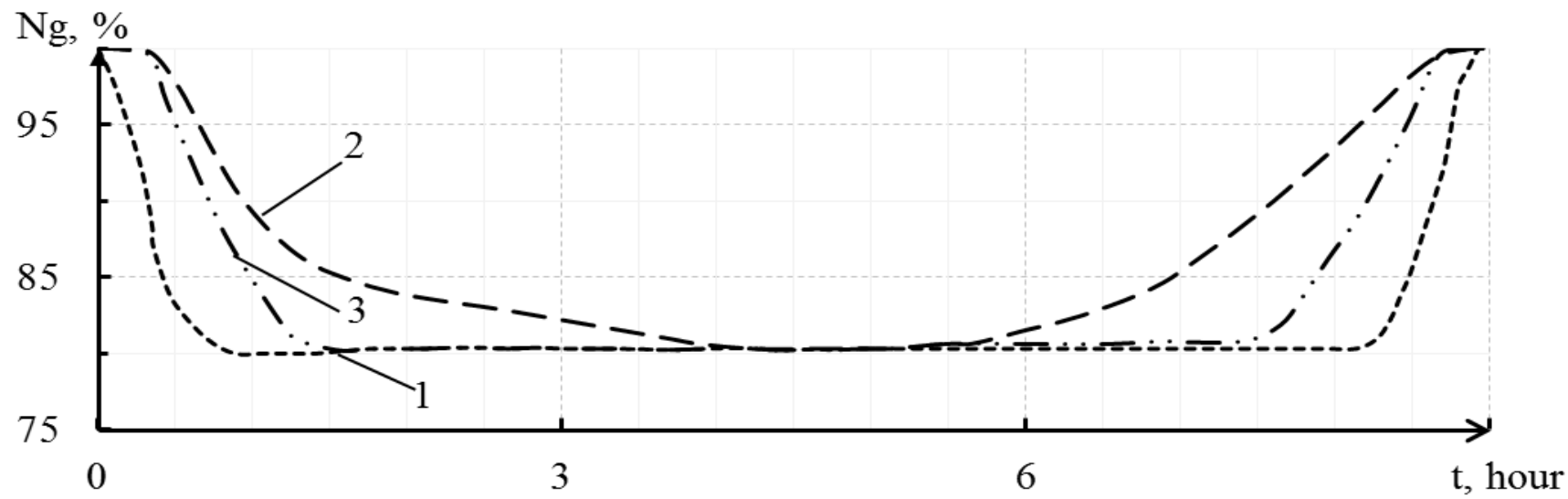

1 - improved ACS with constant average water temperature of the $1^{\text {st }}$ circuit; 2 - improved ACS with constant average water temperature of the $1^{\text {st }}$ circuit, which is designed by Tsyselska T.A.; 3 - primary ACS with constant average water temperature of the $1^{\text {st }}$ circuit

Fig. 6 - The result of position changes of the control rods during daily maneuver with improved ACS of constant average water temperature of the 1 st circuit

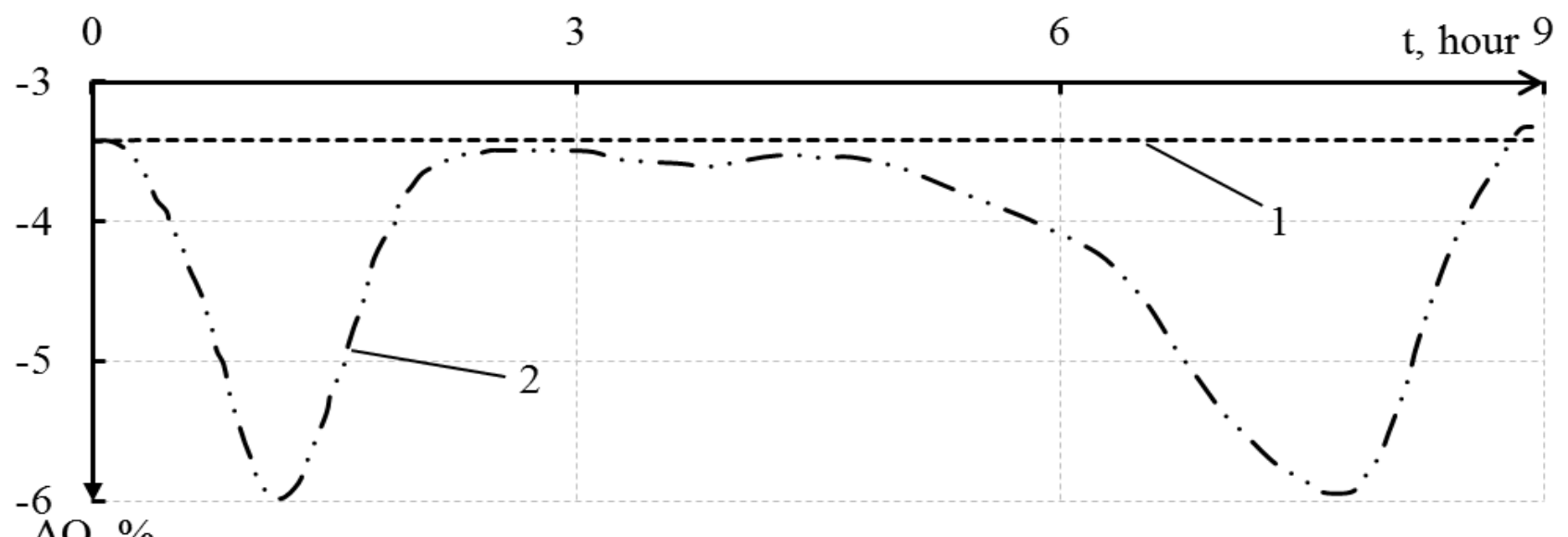

$\mathrm{AO}, \%$

1 - improved ACS with constant average water temperature of the $1^{\text {st }}$ circuit; 2 - primary ACS with constant average water temperature of the $1^{\text {st }}$ circuit

Fig. 7 - The result of AO changes in daily maneuvers 


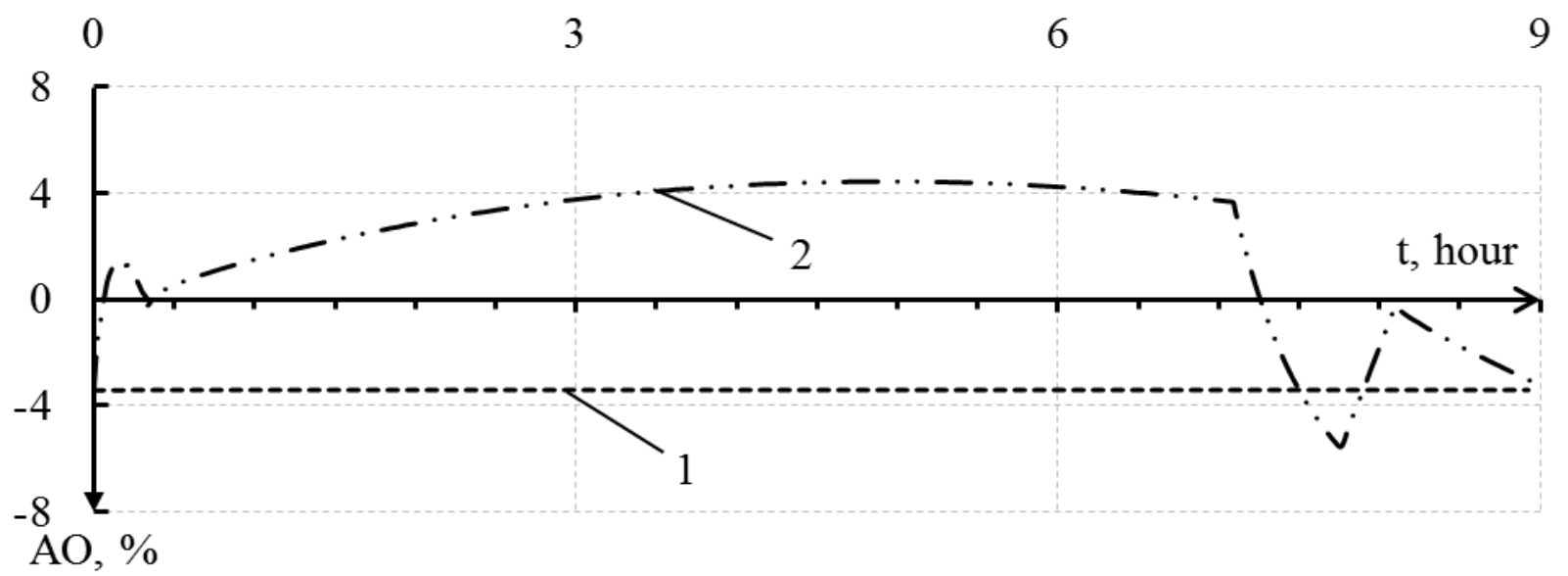

1 - improved ACS with constant steam pressure in the 2 nd circuit; 2 - primary ACS with constant steam pressure in the 2 nd circuit

Fig. 8 - The result of changes in the AO daily maneuvers

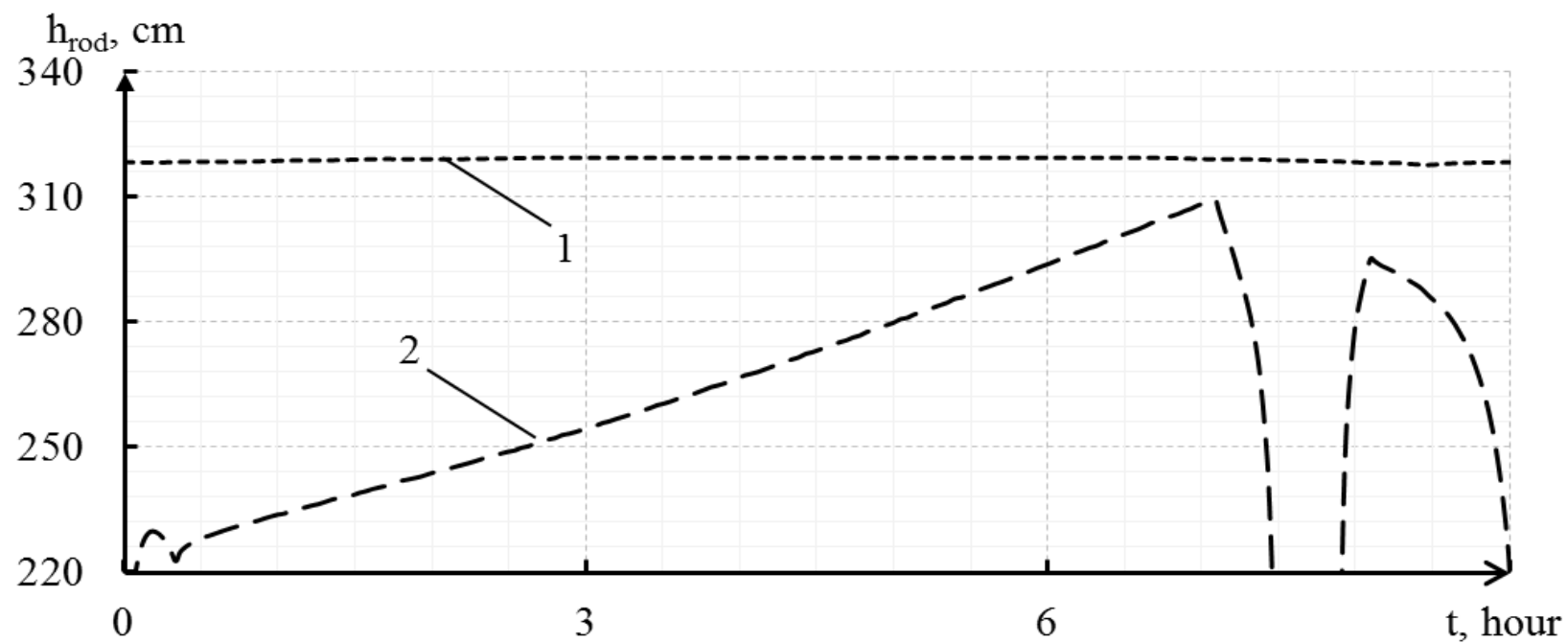

1 - improved ACS with constant steam pressure in the 2nd circuit; 2 - primary ACS with constant steam pressure in the 2 nd circuit

Fig. 9 - The result of position changes of the control rods during daily maneuver

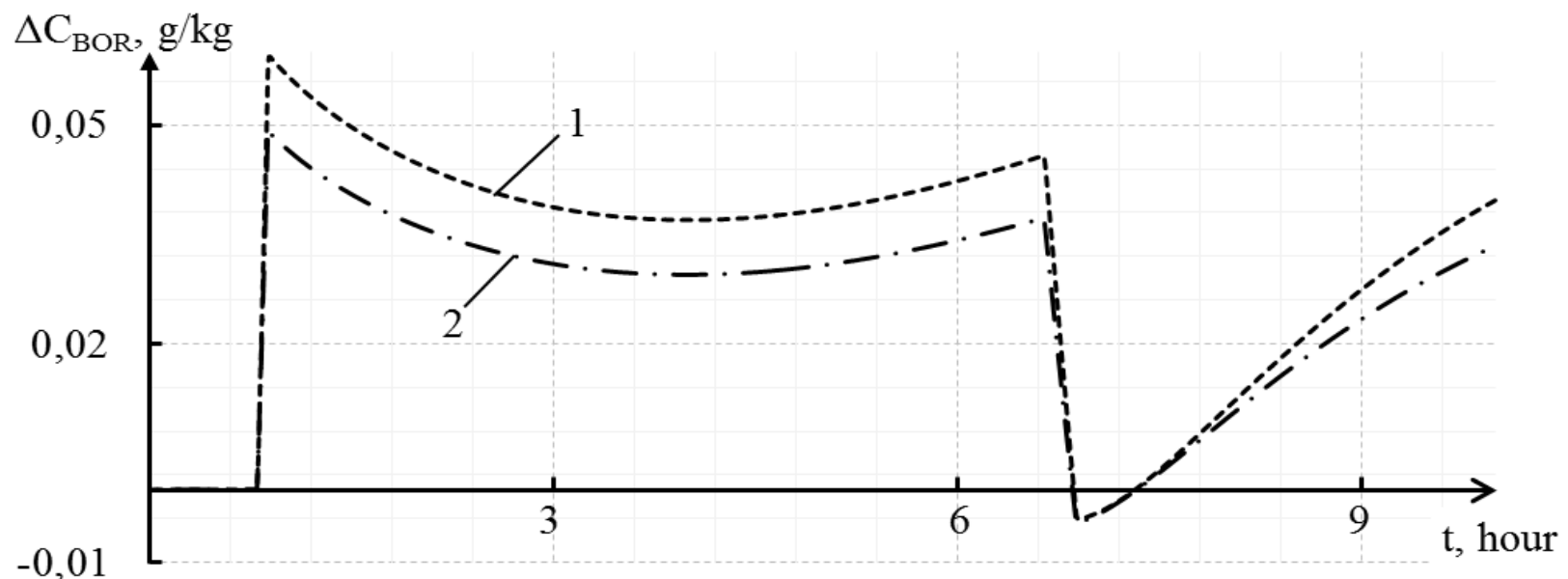

1 - control program with constant average water temperature of the 1st circuit; 2 - control program with constant steam pressure in the 2 nd circuit

Fig. 10 - The result of concentration changes of boric acid during daily maneuver with improved ACS 
The universal method of regulation the power change of NPP with VVER-1000 was designed. It allows to prevent fluctuations of process-dependent parameters and to improve the automated system of control the power change of the power unit. The method of automated control the power change at NPP with VVER-1000 was created for the first time. It uses three control loops. One of which maintains the regulatory change of reactor power by regulating the concentration of boric acid in the coolant, the second circuit keeps the required value of axial offset by changing the position of control rods, and the third one holds constant the coolant temperature mode by regulating the position of the main turbo generator valves.

\section{Conclusions}

The work includes scientific positions of improved automated control system of power change of NPP with VVER-1000 which allows to operate in a load following mode and change the load of the reactor in an automated mode. It improves the stability of energy in the RC to normal operating conditions. It is safe to make the following conclusions:

1. The advantages and disadvantages of each program was discovered after analyzing the existing control programs of power change of NPP with VVER-1000. It should be mentioned that each control program does not include intra-inherent disturbances which can lead to loss of reactor sustainability by changing the energy field. In order to control the power change of NPP with VVER-1000 in a load following mode effectively and safely, a study of the impact power change to AO was made. Thus, it was explored that ensuring a steady state of the reactor must be maintained in a given range by AO which can be considered as a quantitative measure of stability. This measure of stability varies depending on the current power of NPP because AO must be maintained in a load following mode within the prescribed limits.

2. Based on mathematical models, the simulation model of NPP with VVER-1000 was developed in Simulink environment of the Matlab software package. This developed simulation model is different from the known that includes multi-zone simulation model reactor with allocated parameters and allows to take into account the internal- inherent properties of the RC (including transients on xenon). In addition, this model reduces the modeling error of static and dynamic properties of the reactor where the modeling error of neutron power reactor reduces 2.54 times (from 0.0024 to 0.000944); coolant temperature at the output of the RC reduces $10.8 \%$ (from 0.0011 to 0.001012 ); electric power of power unit reduces 1.77 times (from 0.0017 to 0.000956 ).

3. The main advantage of the presented method is the ability to simultaneously use of three control loops, one of which maintains regulatory change of reactor power by controlling the concentration of boric acid in the coolant, the second controls $\mathrm{AO}$ value by changing the position of the control rods of the $\mathrm{RC}$, and the third - the coolant temperature conditions in the first circuit or the steam pressure conditions in the second circuit by controlling the position of the main turbo generator valves. After analyzing of the dynamics of this automated method of power change of NPP with VVER-1000 was found that the stability of energy field in the RC has been improved in a load following mode, such as:

- for the temperature control of the coolant $\langle\mathrm{t}\rangle=$ const: AO module is reduced 1.8 times (from -6 to $-3.41 \%$ );

- for the temperature control of the coolant $\langle\mathrm{p} 2\rangle=$ const: AO module is reduced 1.3 times (from 4.3 to $-3.41 \%$ ).

\section{References}

[1] Lokhov. (2011, Ferbuary 29). Load-following with nuclear power plants. [Online]. Available: https://www.oecdnea.org/nea-news/2011/29-2/nea-news-29-2-load-following-e.pdf;

[2] S. Pelykh, "A way of the WWER-1000 neutron field axial distribution stabilization at power manoeuvring”, Nuclear \& Radiation Safety, Vol. 49, Is. 1, 2011;

[3] T. Foshch, "Analysis of the axial offset of power unit PWR (VVER-1000) in a manoeuvring mode", Odessa Polytechnic University Works, Issue 1(43), pp. 97-103;

[4] Y. Todortsev, "Analysis of methods for controlling power unit with a pressurized water reactor in manoeuvring", Eastern-European journal of enterprise technologies, Vol. 6, Issue 8 (66), pp. 3-10;

[5] T. Foshch, "Analysis of the influence of methods for controlling power unit with a pressurized water reactor for axial offset", Eastern-European journal of enterprise technologies, Vol. 2, Issue 8 (68), pp. 19-27;

[6] T. Foshch, "Control program analysis of constant steam pressure in the second circuit of power unit PWR (VVER1000) while manoeuvring", International Scientific and Practical Conference «Innovative development of industry automation, information and energy-saving technologies - 2013. The current state, problems and prospects», Moscow, 2013, pp. 19-21;

[7] M. Maksimov, "A model of a power unit with VVER-1000 as an object of power control", Odessa Polytechnic University Works, Vol. 38, Is. 1, 2012. 